\title{
The limits of deontology in dental ethics education
}

\author{
Parker Crutchfield ${ }^{1}$ • Jane C. Johnson ${ }^{2}$. \\ Lea Brandt ${ }^{3}$ - David Fleming ${ }^{3}$
}

Published online: 23 March 2016

(C) Springer International Publishing AG 2016

\begin{abstract}
Most current dental ethics curricula use a deontological approach to biomedical and dental ethics that emphasizes adherence to duties and principles as properties that determine whether an act is ethical. But the actual ethical orientation of students is typically unknown. The purpose of the current study was to determine the ethical orientation of dental students in resolving clinical ethical dilemmas. First-year students from one school were invited to participate in an electronic survey that included eight vignettes featuring ethical conflicts common to the health care setting. The Multidimensional Ethics Scale was used to evaluate the students' ethical judgments of these conflicts. Students rated each vignette along 13 ethically relevant items using a 7-point scale. Nine of the thirteen items were analyzed because they represent the dominant ethical theories, including deontology. One hundred sixteen dental students successfully completed the survey. Of the analyzed items, those associated with deontology had comparatively weak associations with whether students judged the action to be ethical and whether students judged themselves likely to perform the action. Whether an action was judged to be caring had the strongest association with whether the action was judged to be ethical and whether students judged themselves likely to perform the action. These results suggest that adherence to duties or principles has weaker association with students' ethical judgments and behavior compared to caring, which was found to be more influential in their ethical judgments and behavior. Current dental school curricula with a primary focus on deontology may not adequately prepare students to maintain ethical attitudes and behavior in practice.
\end{abstract}

Parker Crutchfield

Pcrutchfield@atsu.edu

1 Missouri School of Dentistry and Oral Health, A.T. Still University, Kirksville, MO 63501, USA

2 A.T. Still Research Institute, A.T. Still University, Kirksville, MO, USA

3 Center for Health Ethics, University of Missouri School of Medicine, Columbia, MO, USA 
Keywords Dental education · Curriculum · Principle-based ethics

\section{Introduction}

Providing health care in an ethical manner is a professional imperative that requires analytical knowledge and skill. Like other clinical skills, clinical ethical analysis is learned during professional school and then honed through practice. Education in clinical ethics is common in both medical and dental schools. In the case of dental education, there are no ethical practices widely considered to be the most valuable; nor is there consensus about the comparative importance of ethics in the curriculum or the most effective pedagogical strategies. However, curriculum in ethics is required for national accreditation.

Ethics curricula in dental schools typically use a deontological approach, even though little evidence supports the efficacy of this approach in producing ethical behavior in clinicians. When using a deontological approach, an act is judged right or wrong if it is in accordance with prescribed duties or principles, rather than the consequences of the act itself. Principlism, the most common approach to biomedical and health care ethics, is itself deontological (though it partly originates from consequentialist ethical theories) (Beauchamp and Childress 2001). When using a principlist approach, the morality of an act is determined by whether it accords with duties or principles, of which there are four: autonomy, beneficence, non-maleficence, and justice (Lantz et al. 2011). Principlism would claim that, other things being equal, an act resulting in what seems to be the best medical outcome at the expense of a patient's autonomy is unethical. For example, suppose that a physician violates a patient's advance directive to save him or her and that patient goes on to live a balanced and happy life. Such an act is right according to consequentialism because it maximizes the medical good (the patient's happiness) but wrong according to principlism because it violates the patient's right to make a rational choice for herself. Another example is if producing the best consequences requires harming a patient (e.g. unwanted amputation, even if medically indicated), then according to principlism such an act is unethical. Indeed, the principle, "Do no harm," is derived from the ancient foundation of clinical ethics, even though the principle is often followed without critical examination. When consequences and principles conflict, according to principlism the ethical act is the one in accordance with the principle in question. Relying on principles rather than consequences in such conflicts is what distinguishes between deontology and consequentialism.

Evidence suggests that ethics education in dental schools maintains a focus on a deontological approach to health care ethics (Lantz et al. 2011). The American Dental Association (ADA) uses the four principles of principlism in its Principles of Ethics and Code of Professional Conduct although it adds a fifth principle, veracity that is commonly considered an aspect of autonomy (American Dental Association 2012). Further, the National Board Dental Examinations (NBDE) requires that students answer questions about ethics, but the questions are correct only in the context of principlism. Assuming that ethics educators teach to conform to ADA standards and the exams that govern graduation and licensing, it is reasonable to suppose that they teach principlism, and thus deontology, to a significant extent. Finally, a recent study by Lantz et al. 
(2011) examined ethics education at dental schools across the United States. Their results indicated that every surveyed dental school (100\%) taught the Principles of Ethics and Code of Professional Conduct. Some schools used textbooks strongly influenced by deontology; for example, $65 \%$ used Dental Ethics at Chairside, which uses a deontological approach by grounding discussion of dental ethics in principlism and advocates a hierarchy of values that is derivative of principlism. Further, $46 \%$ tested students' knowledge of principlism, and $27 \%$ used the Defining Issues Test (DIT) and $24 \%$ used the Dental Ethical Reasoning and Judgment Test, both of which have deontology as their ethical background, to assess competence.

Research conducted on the ethical judgments of dental students is almost exclusively based on their performance on the Defining Issues Test (DIT) (Bebeau and Thoma 1994). The DIT is a survey instrument designed to assess personals moral development. It elicits responses to moral dilemmas and then places a person's moral development on a scale similar to that of Kohlberg's model of moral development (Kohlberg 1984; Rest 1979; You and Bebeau 2012). However, the Kohlberg model and contemporary iterations of it are prejudiced towards deontological moral reasoning. Other ethical theories, such as the ethics of care (the view that caring and compassionate relationships are significant components of morality) (Gilligan 1982), are ignored in this model (Rest et al. 1999).

In addition, the DIT uses only five ethical dilemmas, and only one of them pertains to health care. Because ethical judgments and subsequent ethical behavior are situationdependent the utility of the DIT is diminished because it requires that ethical judgments be situation-independent (Doris 2005). It is therefore difficult to generalize responses to the DIT to expected behavior in health care settings. A similar survey, the Dental Ethical Reasoning and Judgment Test, improves on the content of the dilemmas compared with the DIT, but it only offers a limited range of potential actions and justifications, which predominantly presume a deontological framework (Bebeau and Thoma 1999).

Both tests purport to be validated, but their validation depends on the truth of the theory upon which they are based, deontology, and that theory is at best an incomplete picture of our ethical lives and at worst entirely false. Any survey validated with respect to an ethical theory would have the same deficiencies, because the best such instruments can achieve is validation that is conditional on the ethical theory or theories. And in the case of the aforementioned tests the antecedent theory is incomplete or false.

Ethics education in dental schools can be more nuanced and blended than described here, but deontology remains as a main component of dental ethics education and training. However, the actual ethical orientation of students remains unclear. Therefore, the purpose of the current study was to determine the ethical orientations of first-year and second-year dental students. Ethical orientation was determined by which ethical theory was most closely aligned with the student's ethical judgments.

\section{Material and methods}

The current study was part of a larger study designed to improve the care that health professionals provide by comparing their ethical orientations with those of underserved patient populations and using that information to construct a better ethics curriculum 
that prepares students to meet the ethical needs of patients. The current study was exempted from oversight by the local institutional review board.

First-year dental students at an American dental school were surveyed about their ethical orientation. First-year students were selected in order to eliminate the possibility that ethics education during dental school influenced their ethical orientations. This allows more meaningful future comparisons between their ethical orientations upon exiting dental school and more reliable inferences regarding the ethical orientation of entering dental students. A total of three cohorts were surveyed in each cohort's first month of dental school over a period of 2 years. There were 42 students in each cohort. A link to the survey was emailed to all first-year students at the participating school; the email also contained information regarding the risks and benefits of the study and a statement that participation was optional. Clicking on the link to the survey constituted informed consent.

The Multidimensional Ethics Scale was used to evaluate the students' ethical judgments in response to ethical conflicts because it is not prejudicial against any ethical theory and it allows investigators to tailor the content of the ethical conflicts to the relevant context of the subject. The Multidimensional Ethics Scale has been used frequently in business ethics and is validated for multiple professions (Cohen et al. 1996, 1993, 2001, Cohen et al. 1993, 2001; Flory et al. 1992, 1993; McMahon and Harvey 2007)). Although the vignettes of the current study differed from those used in business ethics, the instrument was not modified or adapted in any way and included items relating to justice, egoism, utilitarianism, deontology, and the ethics of care (Cohen et al. 2001). The benefit of the MES is that it depends in no way on the truth of an ethical theory, as the items address equally all candidate theories. There are no assumptions about what is actually right or wrong or what counts as developed or undeveloped. It simply asks what a person believes about a case. This makes the survey adaptable to wide range of contexts. Even so, the instrument used in the current study was further validated by two professional philosophers with research expertise in ethical theory and moral psychology. The survey consisted of eight vignettes, each between 50 and 100 words. Each vignette described an ethical conflict in a health care setting - a conflict that a health care provider (physician, dentist, nurse) could reasonably expect to face at some point in his or her career - and ended with a stated action (Table 1). Two of the vignettes were controls, one of which ended with a stated action that was clearly unethical and the other with a stated action that was clearly ethical. The other six vignettes were less ethically clear, but most were conflicts commonly faced in health care settings. The vignettes were written so as to equitably elicit judgments on a wide range of ethical factors. This specific design was used so that the ethical conflicts commonly encountered in health care settings could be used to determine ethical orientation by assessing how the students would actually respond to conflicts they may experience in clinical practice.

Students were asked to rate the stated action for each vignette along thirteen items using a 7-point scale (Table 2). The items were ethically relevant descriptions of the described action in each vignette that the students were required to rate. For example, students rated how fair, just, beneficial, or caring the action was or how probable it was that the students or their peers would perform the action. Some items were reverse scored for consistent directionality for all items. Each student made 104 assessments of actions (ie, thirteen assessments per vignette). The survey was administered via SurveyMonkey 
Table 1 Vignettes scored by first-year and second-year dental students

\begin{tabular}{|c|c|}
\hline Vignette & Scenario \\
\hline $\begin{array}{l}\text { Control: clearly } \\
\text { unethical }\end{array}$ & $\begin{array}{l}\text { Patient } S \text { visits Dentist } Q \text { and learns that } \mathrm{s} / \text { he requires } \\
\text { treatment } 1 \text { and will suffer without it. Treatment } 1 \text { is } \\
\text { similar to but less serious than treatment } 2 \text {. However, } \\
\text { S's oral health insurance doesn't cover treatment } 1 \text {, but } \\
\text { does cover the more serious treatment } 2 \text {. Q is not in a } \\
\text { financial position to offer treatment } 1 \text { for free, and } S \\
\text { cannot afford it without insurance. }\end{array}$ \\
\hline $\begin{array}{l}\text { Control: clearly } \\
\text { ethical }\end{array}$ & $\begin{array}{l}\text { Physician A treats Patient } \mathrm{T} \text { for a chronic condition. } \\
\text { Patient T works for very large Company } \mathrm{C} \text { in the same } \\
\text { town as Physician A's practice and provides health } \\
\text { insurance for Patient T. The insurer has contacted } \\
\text { Company C about a rise in costs. Company C calls } \\
\text { Physician A and asks about Patient T's treatment and } \\
\text { says that since they are paying for insurance they ought } \\
\text { to know what they are purchasing. }\end{array}$ \\
\hline
\end{tabular}

Firing patient Physician X works in a hospital and routinely treats Patient S. Patient S never complies with Physician X's prescriptions, but still continues to visit with medical complaints, each time taking up the time of other patients, who must wait. After not complying, Patient S visits with a serious medical issue that will require compliance and follow-up care. This requires more of Physician X's time and effort, which will not be directed at other patients.

Elderly and Physician Y has 20 doses of a vaccine for a disease that children first causes significant suffering for healthy adults but can kill the elderly or children. When Physician Y opens in the morning there are 50 people standing in line for the vaccine. Those first in line are healthy adults and those in the back of the line are older adults and children with their parents.

Refusing vaccines Patient $\mathrm{M}$ is visiting Pediatrician $\mathrm{R}$ with Child F. Patient $\mathrm{M}$ belongs to a culture that strongly believes that vaccines ought not be given to children. Pediatrician $R$ explains to Patient $M$ that vaccines are safe and that refusing vaccines for Child $\mathrm{F}$ puts Child $\mathrm{F}$ at a higher risk for potentially fatal diseases. Pediatrician $\mathrm{R}$ also explains that by not giving Child $\mathrm{F}$ vaccines, Patient $\mathrm{M}$ is endangering other children who are too young to receive vaccines.

Moving practice Dentist $Z$ has been practicing dentistry in the same building in city $\mathrm{W}$ for 30 years. During this time, Dentist $Z$ has established close relationships with most of the patients and even their children and grandchildren. One night, Dentist Z's practice burns down. Over the 30 years, property values in city $\mathrm{W}$ went up so high that to rebuild and continue to care for the patients in $\mathrm{W}$ would require $\mathrm{Z}$ to sacrifice most of the profit from the practice.

Special care for Dentist $\mathrm{R}$ is an associate at an office run by two partners. one patient

Dentist $\mathrm{R}$ has been treating Patient $\mathrm{C}$ for several years, and the two have established a close relationship. Patient $\mathrm{C}$ is poor and is taking care of his/her elderly
Action

Q performs treatment 1 but reports to the insurance company treatment 2 .

Physician A refuses to provide information about Patient T.

Physician X tells Patient S to stop visiting so that $\mathrm{s} / \mathrm{he}$ can use the time to treat other patients.

Physician Y provides the vaccine to the elderly and children in the back of the line first, and none is left for the healthy adults in the front of the line.

Patient $\mathrm{M}$ refuses vaccines for Child F.

Dentist $Z$ builds a new practice in a cheaper city to treat underserved patients and refers all of the old patients to a different dentist.

Dentist $\mathrm{R}$ continues to provide rides and free care to Patient $\mathrm{C}$. 
Table 1 (continued)

\begin{tabular}{|c|c|c|}
\hline Vignette & Scenario & Action \\
\hline & $\begin{array}{l}\text { parents, and cannot easily travel to the office. Dentist } \mathrm{R} \\
\text { offers Patient } \mathrm{C} \text { to provide rides to the office and } \\
\text { perform most dental work for free. Other patients find } \\
\text { out about this, and complain to the partners about not } \\
\text { getting the same free work. They ask Dentist } \mathrm{R} \text { to stop } \\
\text { providing free care, saying that it is unfair to the other } \\
\text { patients. }\end{array}$ & \\
\hline Ignoring patient & $\begin{array}{l}\text { Nurse N has become good friends with a long-term Patient } \\
\text { Q in a hospital. Nurse N has cared for Patient Q nearly } \\
\text { every day of Q's stay in the hospital, and is happy that } \\
\text { Q will be leaving soon. Nurse N and Patient Q are from } \\
\text { different cultures, and people from Nurse N's culture } \\
\text { discourage relationships with people from Patient Q's } \\
\text { culture. Nurse N's family visits her at work and they } \\
\text { see Patient Q, who happily greets them. }\end{array}$ & Nurse $\mathrm{N}$ ignores Patient Q. \\
\hline
\end{tabular}

(www.surveymonkey.com) during a break between class sessions and took approximately $25 \mathrm{~min}$ to complete. The order of the vignettes was randomized for each student respondent to minimize any bias caused by the order in which they appeared.

The analysis of the student's responses focused on the items describing the various ethical theories. Fairness is often the basis of whether an act is judged to be just: even

Table 2 Ethical items scored by first-year and second-year dental students for each vignette

\begin{tabular}{|c|c|c|c|}
\hline \multicolumn{3}{|l|}{ Score } & \multirow{2}{*}{$\begin{array}{l}\text { Reverse } \\
\text { scored }\end{array}$} \\
\hline 1 & $\begin{array}{lllll}2 & 3 & 4 & 5 & 6\end{array}$ & 7 & \\
\hline Just & & Unjust & $*$ \\
\hline Unfair & & Fair & \\
\hline $\begin{array}{l}\text { Not self-promoting for the person doing } \\
\text { the action }\end{array}$ & & $\begin{array}{l}\text { Self-promoting for the person doing } \\
\text { the action }\end{array}$ & \\
\hline $\begin{array}{l}\text { Personally satisfying for the person doing } \\
\text { the action }\end{array}$ & & $\begin{array}{l}\text { Not personally satisfying for the } \\
\text { person doing the action }\end{array}$ & $*$ \\
\hline Produces the greatest utility & & Produces the least utility & $*$ \\
\hline Minimizes benefits & & Maximizes benefits & \\
\hline Maximizes harm & & Minimizes harm & \\
\hline Does not violate an unwritten contract & & Violates an unwritten contract & * \\
\hline Violates an unspoken promise & & Does not violate an unspoken promise & \\
\hline Shows compassion or caring & & Shows no compassion or caring & $*$ \\
\hline $\begin{array}{l}\text { High probability that I would take the } \\
\text { same action }\end{array}$ & & $\begin{array}{l}\text { Low probability that I would take the } \\
\text { same action }\end{array}$ & $*$ \\
\hline $\begin{array}{l}\text { High probability that my peers would } \\
\text { undertake the same action }\end{array}$ & & $\begin{array}{l}\text { Low probability that my peers would } \\
\text { undertake the same action }\end{array}$ & $*$ \\
\hline The action described above is ethical & & $\begin{array}{l}\text { The action described above is } \\
\text { unethical }\end{array}$ & $*$ \\
\hline
\end{tabular}


though one component of principlism is justice, principlism makes no claim that justice is fairness. Consequences like benefits and harms are factors that determine whether an act is ethical, according to utilitarianism. Principles like upholding contracts and keeping promises are the basis for deontological theories such as principlism. Whether an act is caring or compassionate helps determine the ethics of an act, according to the theory of ethics of care. The other items evaluated were the probability that one would perform the same action described in the vignette and the probability that one's peers would perform the same action. These items were included to determine how the respondent would act if faced with a similar conflict. After two cohorts had participated, it was clear that many participants were unclear about the meaning of 'utility', so for the third cohort the term, 'happiness,' was substituted.

General linear mixed models were used to determine which items were related to how ethical or unethical the students thought the stated action of the vignette was. Additional linear mixed models were used to determine which items were related to how likely the students judged themselves to perform the vignettes' stated actions. The regression coefficients from these linear mixed models were examined to test which items were most strongly associated with the ethical score and with the probability of the students performing the stated action of the vignette. Due to the large number of statistical tests being conducted, $P \leq .001$ were considered statistically significant. Analyses were conducted using SAS 9.3 (SAS Institute Inc., Cary, NC).

\section{Results}

The survey link was distributed to 126 first-year dental students dental students; 116 $(91 \%)$ provided valid responses. The mean (SD) age was $24.9(3.3)$ years with a range of 21-37 years, and 72 (62\%) respondents were women. Most students (80, $75 \%$ ) reported that they had had previous ethics education in school.

We analyzed the items that students rated for each vignette. Summary statistics of those items and how ethical the action was judged to be for each vignette are presented in Table 3. The mean (SD) scores on the ethical item for the control vignettes were 5.5 (1.7) for the clearly unethical vignette and 2.2 (1.8) for the clearly ethical vignette. Of the other six vignettes, the "moving practice" vignette was scored as most ethical (mean [SD], 2.4 [1.5]) and the "ignoring patient" vignette was scored as least ethical (mean [SD], 5.7 [1.7]).

The regression coefficients and tests of associations of the items with how ethical the action was judged to be are presented in Table 3 and Fig. 1. Shows caring and high probability that the student would perform the action were most often associated (statistically significant test of association with regression coefficient of $>.5$ ) with the ethical score (6 [75\%] vignettes). Self-promoting and personally satisfying, were least often associated with the ethical score (0 [0\%] vignettes). The items most or second most strongly associated with the ethical score (largest or second largest regression coefficient) were high probability that the student would perform the same action (6 [75\%] vignettes; 2 [25\%] most strongly, 4 [50\%] second most strongly) and shows caring (4 [50\%] vignettes; 3 [38\%] most strongly, 1 [13\%] second most strongly).

The regression coefficients and tests of associations of the items with the probability that the student would perform the same action are presented in Table 3 and Fig. 2. 


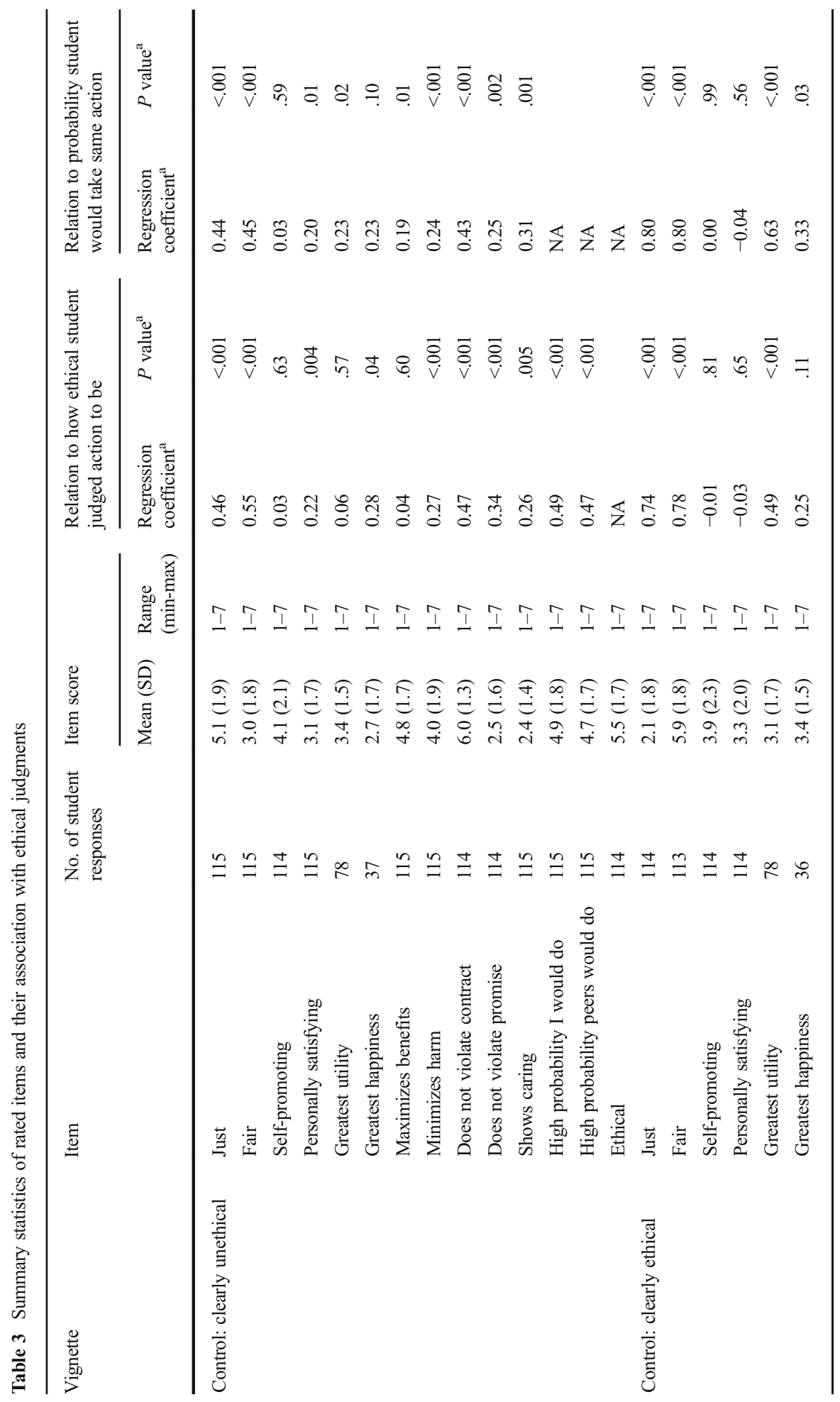




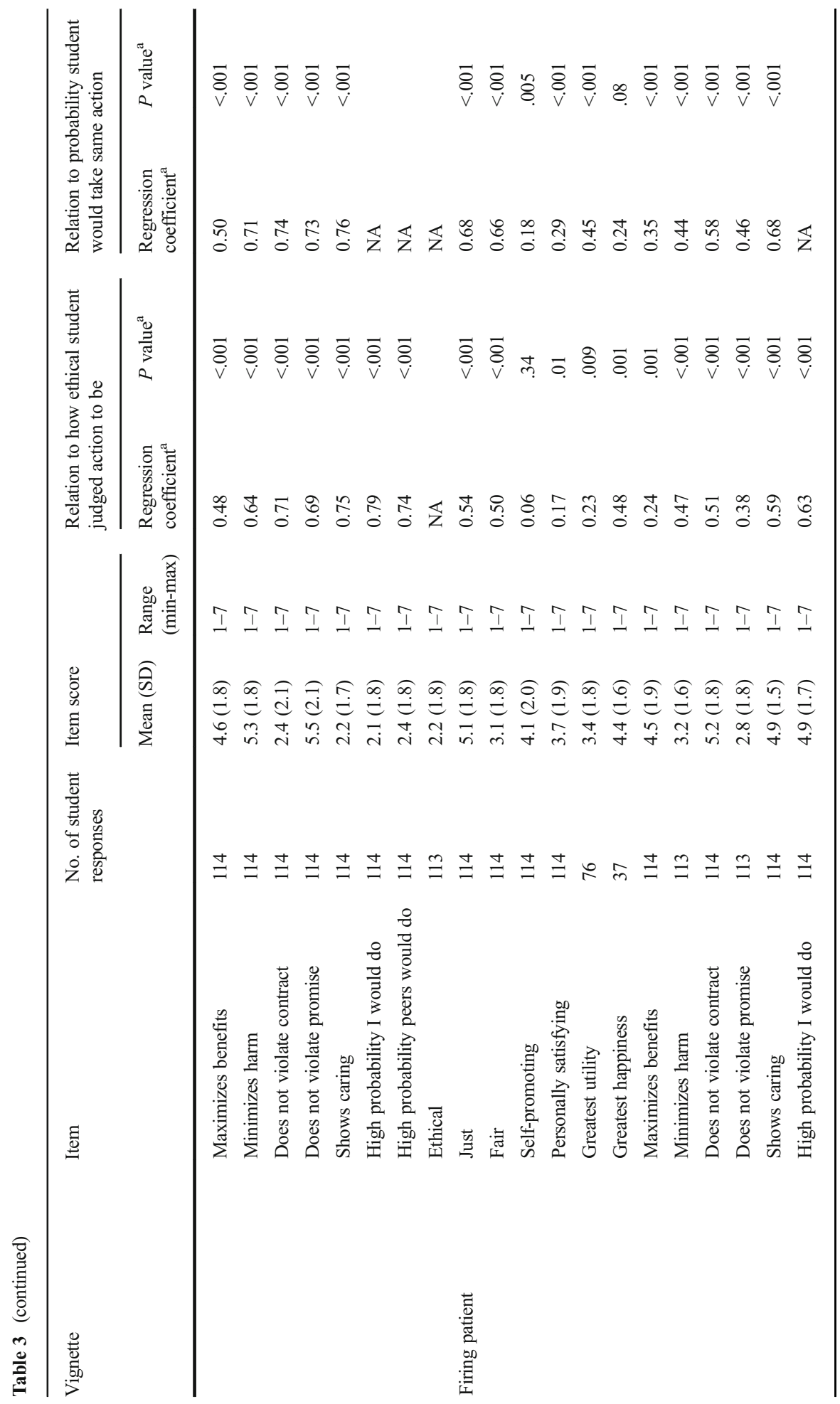




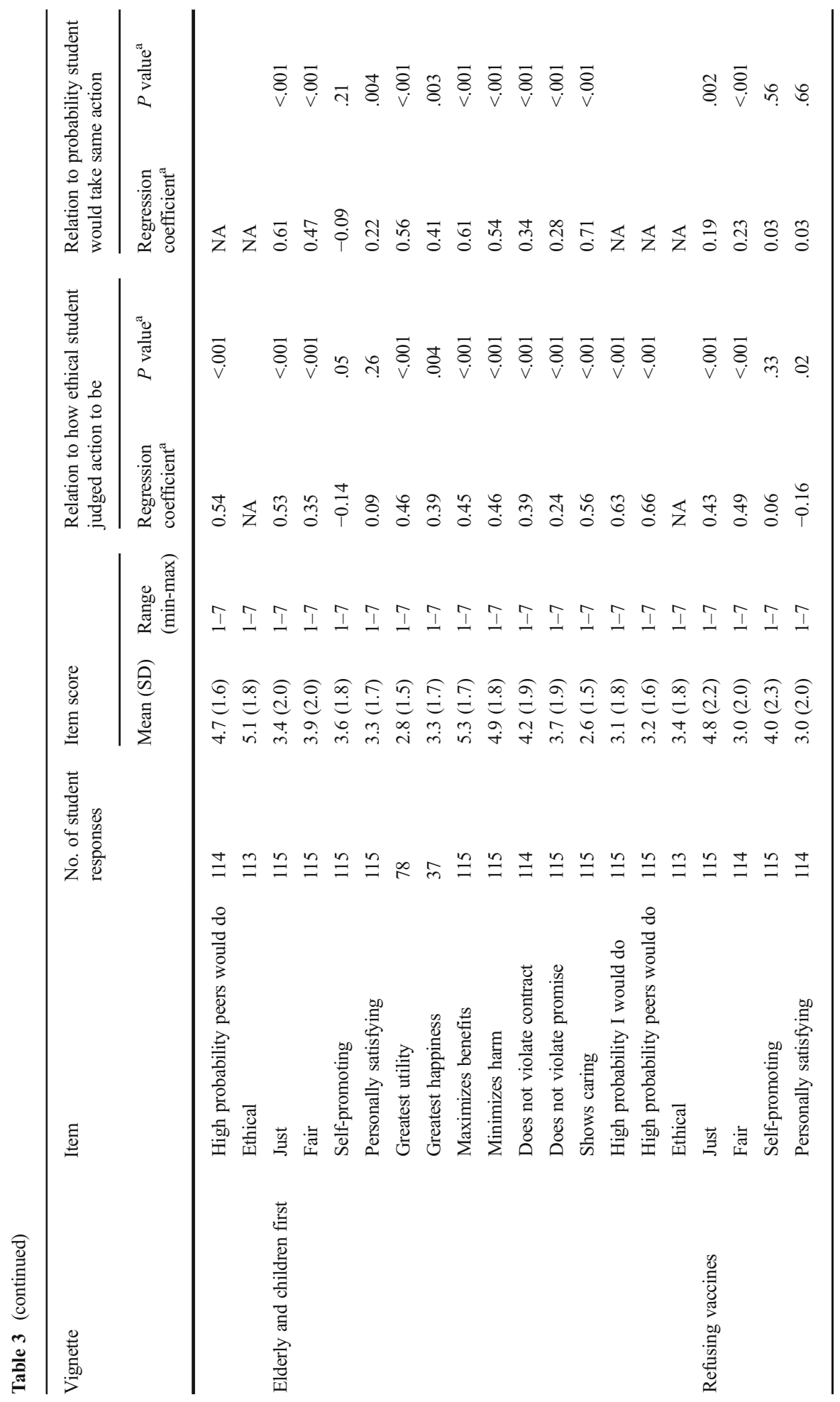




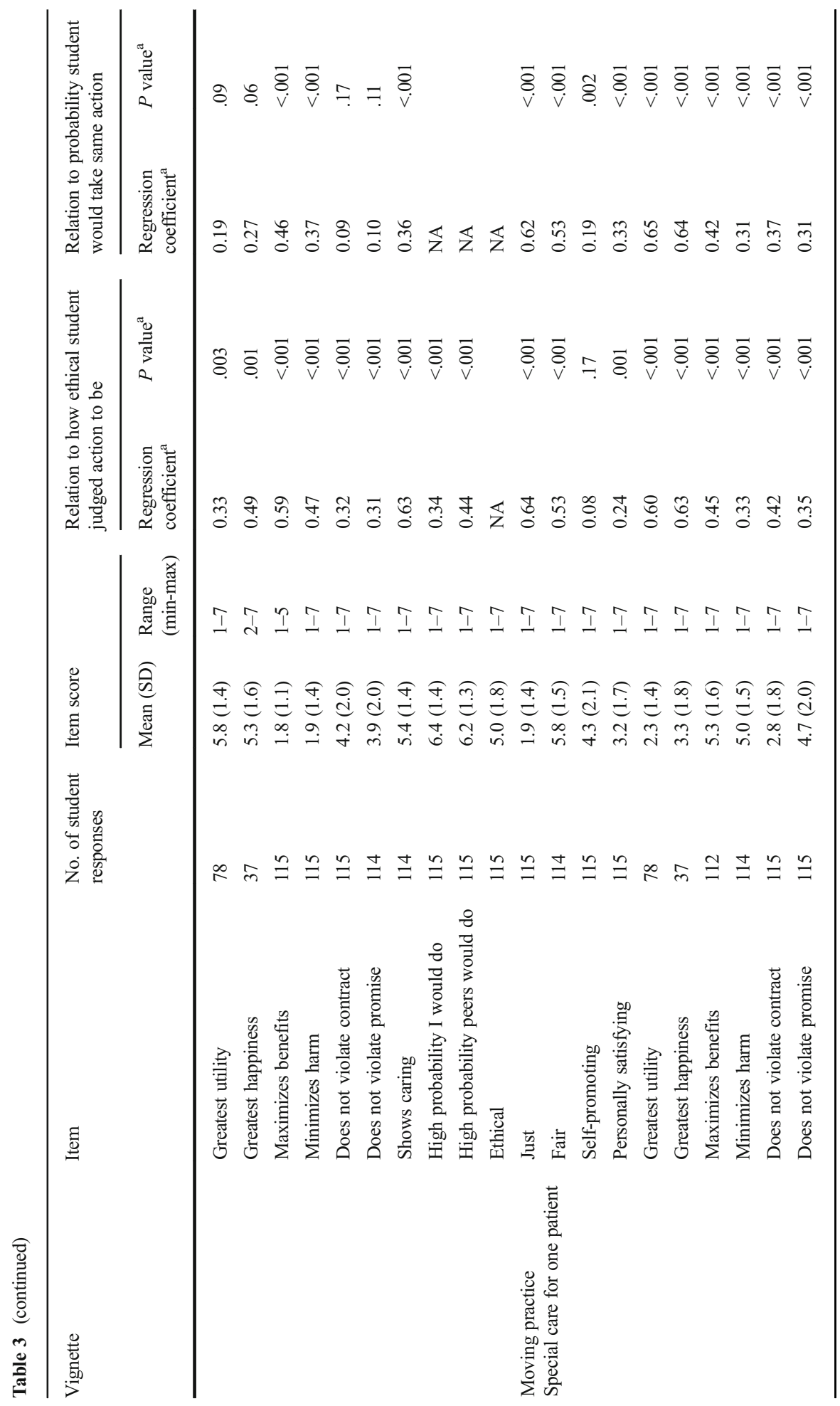




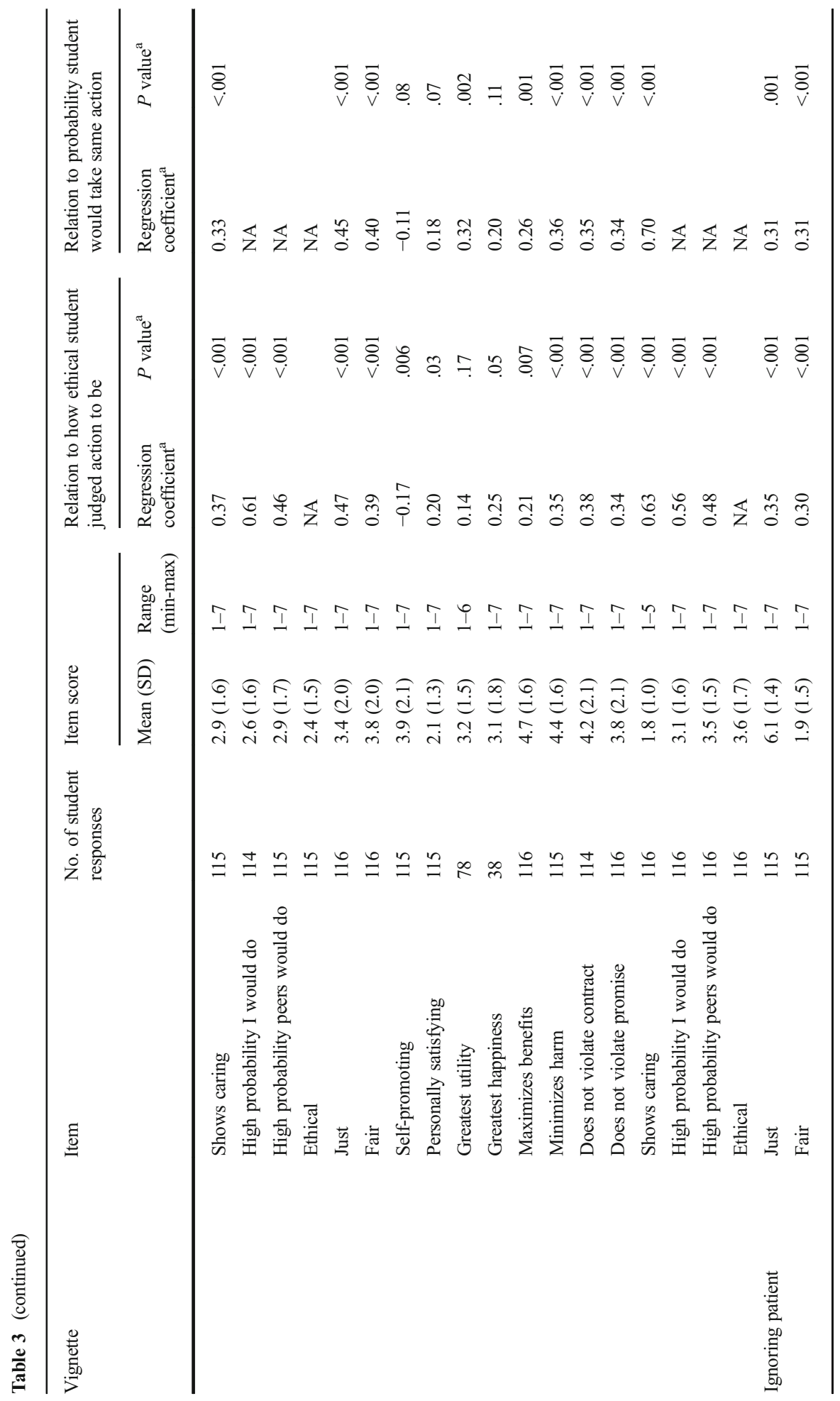




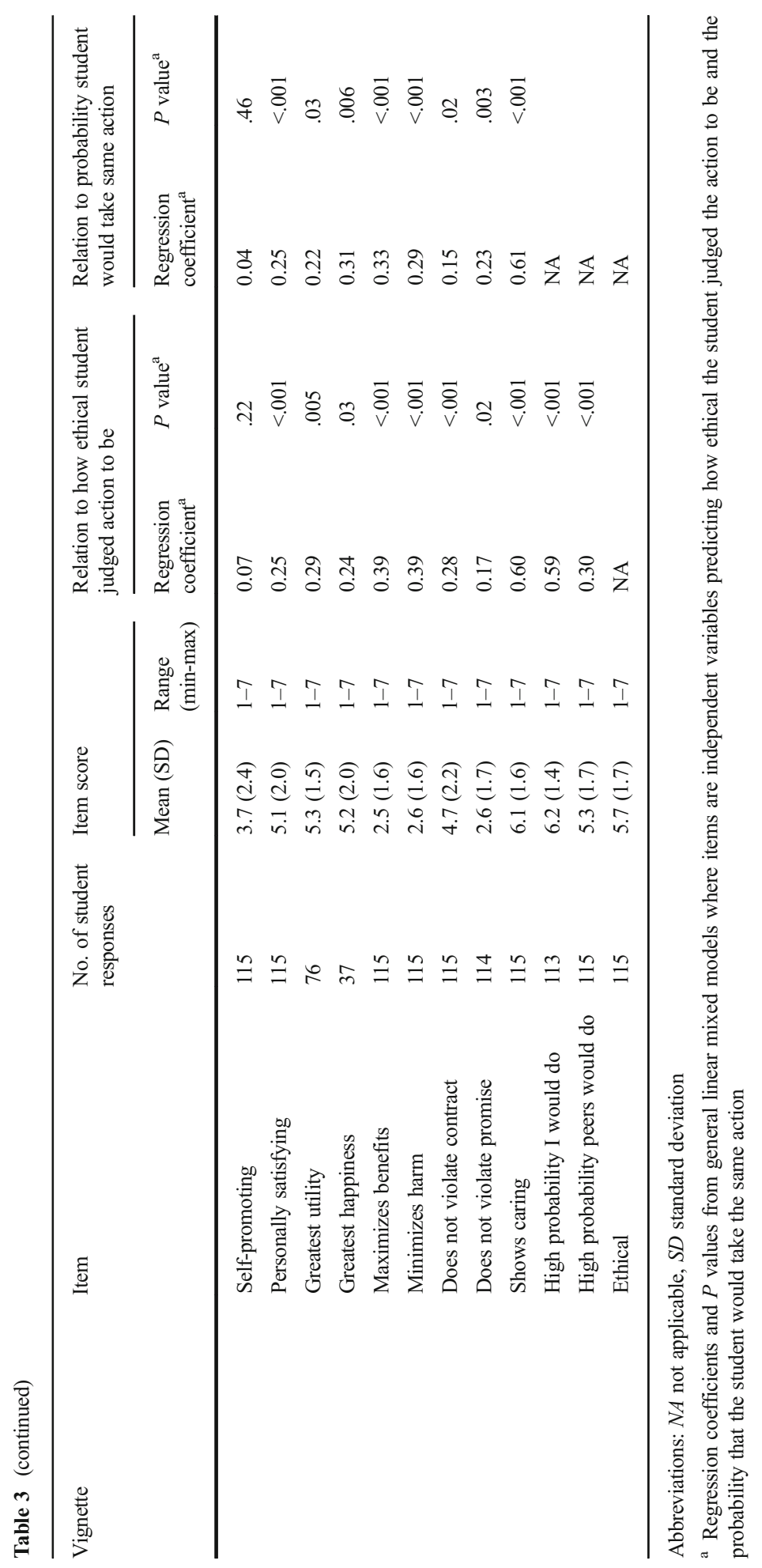




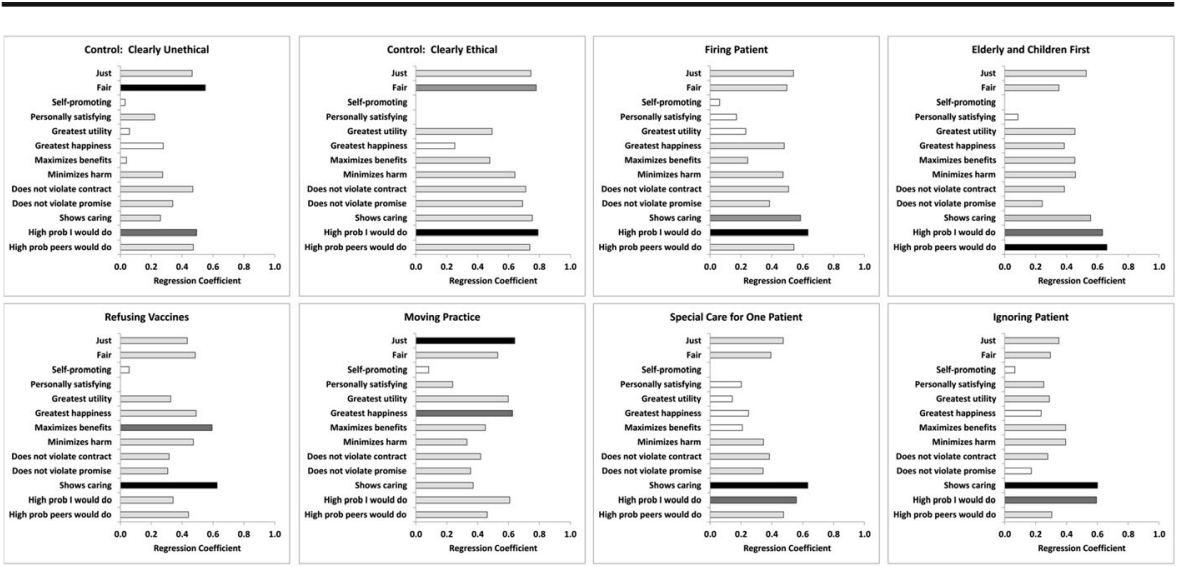

Fig. 1 Item associations with how ethical act is judged as being. Black bar indicates strongest association. Shaded bar indicates second strongest association

Shows caring was most often associated (statistically significant test of association with regression coefficient of $>.5$ ) with the probability the student would perform the action score (5 [63\%] vignettes). The items most or second most strongly associated with the probability the student would perform the action score (largest or second largest regression coefficient) were shows caring (4 [50\%] vignettes; 3 [38\%] most strongly, $1[13 \%]$ second most strongly) and just (4 [50\%] vignettes; 2 [25\%] most strongly, 2 [25\%] second most strongly).

\section{Discussion}

Whether an act was judged as caring was most frequently associated with whether an act was judged as ethical. Furthermore, when that factor was associated, it exhibited the strongest association in three vignettes and second strongest in one. So, not only was it most frequently associated with whether the act was judged to be ethical, it also exhibited the strongest associations. In contrast, deontological factors like keeping promises or contracts were associated with whether the act was ethical in only two of the eights vignettes and in no vignette did either of them exhibit the strongest or second strongest association.

Whether an act was judged as caring also exhibited strong associations with whether students judged themselves likely to perform the act. In five of the eight vignettes, caring exhibited an association, and in four of those it exhibited the strongest or second strongest association. The justice of the act was associated with students' judgments about whether they would perform the act in four of the eight vignettes, and in each of those it exhibited the strongest or second strongest association (with a regression coefficient of >.5). Keeping promises or contracts were associated with whether students judged themselves likely to perform the act in only two of the eight vignettes, one of which was the control, a vignette for which all items should exhibit a strong association. And in no vignette did either of these factors exhibit the strongest or second strongest association. Because results from the students' responses to the control vignettes were as expected, it seems likely that these results are a good reflection of the ethical orientation of survey respondents in these and similar situations. 


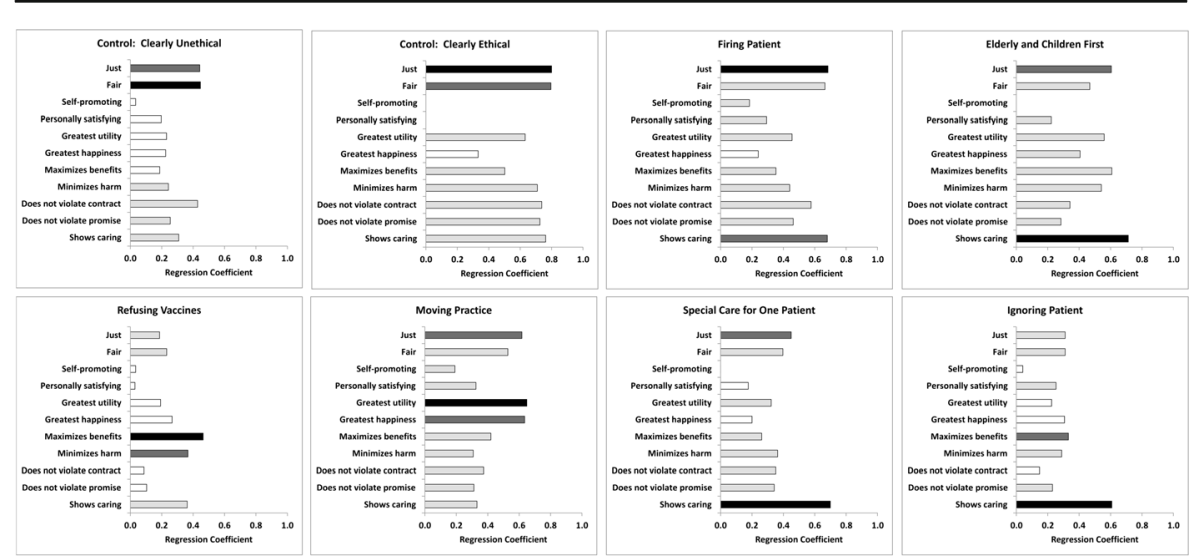

Fig. 2 Item associations with how likely student judged he or she would perform the act. Black bar indicates strongest association. Shaded bar indicates second strongest association

However, it should be noted that few individuals maintain a stable ethical orientation or have a primary ethical orientation. And although 'happiness' was substituted for 'utility' in one of the items, this change in no way diminishes the strength and frequency of the associations with caring or increases the strength or frequency of such associations with deontological items. Additionally, given that these items and the items relating to the ethics of care and deontology are independent of each other, the substitution didn't influence the outcomes. Additionally, in several of the vignettes these individual items exhibited significant, and in one case very strong, associations, which indicates that the power was sufficient to detect those associations, if present.

Although deontology is a major component of ethics curriculum and assessment in dental education, these results indicate that the ethics of care is a significant component of the ethical orientation of students. Not only are judgments about caring frequently associated with judgments about whether an act is ethical, they are also frequently associated with judgments about whether one is likely to perform the act. Justice also exhibited frequent and strong associations; though they were not as frequent or as strong as those for caring. Deontological factors such as keeping promises or contracts did not exhibit frequent or strong associations. And even though the results were generally scattered, these associations or lack of associations in the case of the deontological factors have been, to our knowledge, not previously observed.

The ethics of care is presently not a significant component of ethics education in dental schools, given the focus on deontology and the reliance of dental schools on materials and assessments that altogether ignore ethics of care. Moreover, of the dental schools that Lantz et $\mathrm{l}^{1}$ surveyed, only $59 \%$ of them responded that they taught the related concept of compassion, and even then only in the context of virtue theory (which is a theory about the normative properties of a person's character that has little relevance to student judgments about actions that are ethical or unethical). Given our results, this disparity of focus may be detrimental to the goals of ethics education and to the future ethical behavior of dentists, insofar as the widespread content of ethics education is potentially in conflict with how students are prepared to judge and act.

Knowing the patterns of students' ethical judgments can help educators tailor curricula to those patterns. Our results suggest limitations of deontology for dental 
education and the potential importance of teaching the ethics of care. Dental education should include content that will effectively produce the desired outcome, which in the case of ethics education is ethical behavior. Since our results suggest that violation of duties or principles was not typically associated with judgments about how a student was likely to behave, a curriculum that focuses on acting in accordance with principles is counterproductive, if the content is contrary to how students are inclined to act. Therefore, including curriculum that emphasizes caring or compassionate attitudes may be more expedient for inducing ethical behavior in dental students, perhaps as part of a pluralistic approach to ethics education. Such an approach should include content on professional codes and biomedical ethical theory since no biomedical ethics curriculum would be complete without including content about the theories and history of the field. But this approach could also include narratives from people belonging to vulnerable populations, films, fiction, interviews with standardized patients, role-play between students, community service, or other activities and assessments so that the ethics of care is included in the curriculum. This recommendation assumes that education can alter a person's judgments and subsequent behavior, but this is an assumption that almost every educator accepts.

A pluralistic approach is further justified by the data from Lantz et al. (2011), who noted that the average number of hours spent in dental school on stand-alone ethics curriculum was $26.5 \mathrm{~h}$. Given this limited time, the ethics curriculum in dental school should present diverse ethical theories instead of focusing on deontology, especially considering that deontology seems to have little influence on how dental students are likely to act, at least during the first year. Focusing on deontology may be a path to ethical behavior of great resistance, and therefore an inefficient curriculum to ensure ethical clinicians.

Even though our results suggested first-year dental students associated actions that showed caring or compassion with whether they judged the action to be ethical and whether they would perform the action, it is unknown if this association will persist throughout dental school. Further, it is unknown if caring will persist as an important factor in ethical judgments. Future research should investigate these long-term associations. Considering the results of our study, many students seem to matriculate ready to make ethical judgments and perform ethical acts based upon caring or compassionate relationships.

Future research should also measure the effect that different ethics curricula have on the ethical judgments and ethical orientations of dental students. Only then can an ethics curriculum be constructed that best prepares students to be ethical practitioners.

Although the results of the current study have a high degree of statistical significance, there are limitations. For instance, students who participated may have selfselected, biasing the results. However, the response rate was high (91\%), so it is unlikely that there was a self-selection bias. Further, the students may have answered the survey questions choosing to answer what they thought was expected of them rather than what they actually thought. But the presumption of honesty is required for all survey research.

Of the students surveyed, most $(75 \%)$ had had ethics education prior to dental school. Though it's impossible to say exactly how this influenced their orientations, the prevalence of prior ethics education does not rebut our conclusions. The trends in dental ethics curriculum are not unique to dental ethics. Deontology is emphasized in 
ethics curriculum on first-order moral theory (along with utilitarianism), and in biomedical ethics. If prior ethics education influenced the students' ethical orientations, one would expect that their orientations exhibit stronger associations between the deontological items and the items relating to their judgments about whether the act was ethical or whether they would perform the act themselves.

One limitation is that other than the study by Lantz et al. (2011) little research has been conducted on ethics curricula in US dental schools (Sharp and Kuthy 2008). This gap should be closed in part by future research, in which the baseline information collected in the current study can be used to compare how ethical orientations change over the course of dental school and how ethics curricula engender these changes. Another limitation is that results from the dental students surveyed in the current study may not be generalizable to other populations. The dental school where the survey was conducted attracts and actively recruits a specific type of student who has a clear commitment to service and treatment of underserved populations. Thus, the students in the current study may have had a more pronounced ethics of care orientation that would not be exhibited by dental students elsewhere. Future survey studies should include dental students at other dental schools.

\section{Conclusion}

Results of the current study have important implications for ethics curricula in dental education, and potentially that of other health professions. Considering that the firstyear surveyed tended to associate actions that were judged to be caring (and to a lesser extent, actions that were judged to be just) with whether they judged those actions to be ethical and with the probability that they would perform the same action, a pluralistic approach to ethics education may offer an optimal way for students to think about ethical conflict in health care settings and how they judge themselves likely to behave.

\section{Compliance with ethical standards}

Disclaimer The content is solely the responsibility of the authors.

\section{References}

American Dental Association. Principles of Ethics and Code of Professional Conduct. 2012. At: http://www. ada.org/194.aspx. Accessed: April 7, 2015.

Beauchamp, T.L., and J.F. Childress. 2001. Principles of biomedical ethics. Oxford University Press.

Bebeau, Muriel J., and Stephen J. Thoma. 1999. 'Intermediate' concepts and the connection to moral education. Educational Psychology Review 11(4): 343-361.

Bebeau, M.J., and S.J. Thoma. 1994. The impact of a dental ethics curriculum on moral reasoning. Journal of Dental Education 58(9): 684-92.

Cohen, Jeffrey R., Laurie W. Pant, and David J. Sharp. 2001. An examination of differences in ethical decision-making between Canadian business students and accounting professionals. Journal of Business Ethics 30(4): 319-336. 
Cohen, Jeffrey, Laurie Pant, and David Sharp. 1993. A validation and extension of a multidimensional ethics scale. Journal of Business Ethics 12(1): 13.

Cohen, J.R., L.W., Pant, and D.J. Sharp. 1996. Measuring the ethical awareness and ethical orientation of Canadian auditors. Behavioral Research in Accounting 8 (Supplement).

Doris, John. 2005. Lack of character. Cambridge: Cambridge University Press.

Flory, Steven M., Thomas J. Phillips, and Donald P. Robin. 1993. A reply to a comment on multidimensional analysis of selected ethical issues in accounting. The Accounting Review 68(2): 417-421.

Flory, Steven M., Thomas J. Phillips, R. Eric Reidenbach, and Donald P. Robin. 1992. A multidimensional analysis of selected ethical issues in accounting. The Accounting Review 68(2): 284-302.

Gilligan, C. 1982. In a different voice. Cambridge: Harvard University Press.

Kohlberg, L. 1984. The psychology of moral development: the nature and validity of moral stages. Harper \& Row.

Lantz, Marilyn S., Muriel J. Bebeau, and Pamela Zarkowski. 2011. The status of ethics teaching and learning in U.S. dental schools. Journal of Dental Education 75(10): 1295-309.

McMahon, Joan Marie, and Robert J. Harvey. 2007. Psychometric properties of the Reidenbach-Robin multidimensional ethics scale. Journal of Business Ethics 72(1): 27-39.

Rest, J.R. 1979. Revised manual for the defining issues test: an objective test of moral judgment development. Minnesota Moral Research Projects.

Rest, J.R., M.J. Bebeau, D.N ez, and S.J. Thoma. 1999. Postconventional moral thinking: a Neo-Kohlbergian approach. Taylor \& Francis.

Sharp, H.M., and R.A. Kuthy. 2008. What do dental students learn in an ethics course? an analysis of studentreported learning outcomes. Journal of Dental Education 72.

You, Di, and Muriel J. Bebeau. 2012. Gender difference in ethical abilities of dental students. Journal of Dental Education 76(9): 1137-49. 